\title{
Role of Administration of Beta Receptor Blockers in the Management of Traumatic Brain Injury \\ Samir Mohamed Attia ${ }^{1}$, Mostafa Mahmoud Nabeeh ${ }^{2}$, Mohamed El-Said Ahmed ${ }^{3}$, Mohammed El-Atabani Abdel-Khalek Mohammed ${ }^{4}$ \\ Departments of ${ }^{1}$ Vascular Surgery, ${ }^{2}$ Neurosurgery, ${ }^{3}$ Critical Care Medicine and \\ ${ }^{4}$ Emergency Medicine - Faculty of Medicine - Mansoura University \\ *Corresponding author: Mohammed El-Atabani Abdel-Khalek, Mobile: (+20) 0101161 3243, \\ E-Mail: moh3tbani1991@gmail.com
}

\begin{abstract}
Background: Severe traumatic brain injury (TBI) is associated with paroxysmal sympathetic hyperactivity (PSH), which is characterized by catecholamine surge. $\beta$-blockers can break this cycle by protecting $\beta$-receptor rich brain cells to decrease the cerebral oxygen demand, which may attenuate cerebral ischemia and secondary brain injury. In addition, $\beta$-blockers are beneficial to decrease hypermetabolism, lighten cardiac workload and ischemia, and lessen cerebral oxygen demand in head injury.

Objective: The purpose of the study was to evaluate the effect of beta blockers (propranolol) on patients with acute TBI.

Patients and methods: A total of 400 patients who were presented and admitted to Mansoura University Emergency Hospital (MUEH) surgical ICU with TBI were enrolled in this study. The enrolled patients were divided equally and randomly into 2 groups: Propranolol group (200 patients) who received IV propranolol and control group (200 patients) who received the standard medical and surgical care without propranolol.

Results: The clinical outcome of the studied cases were obviously better in propranolol group ( $\mathrm{P}<0.05)$. The neurologic examination; according to GCS; was improved in 34\% vs. $27.5 \%$. The cardiac examination; according to ECG showed changes in $12 \%$ vs. $26.5 \%$ in propranolol and control groups respectively. Also, the secondary outcome assessment parameters including ICU length of stay (LOS), ward LOS, mechanical ventilation, ventilation periods, survival rate and unfavorable GOS were better in propranolol group $(\mathrm{P}<0.05)$.
\end{abstract}

Conclusion: Early propranolol administration is associated with post-head injury cardioprotective and neuroprotective effects, lower hospital resources use and better functional outcome.

Keywords: Beta Receptor Blockers, ICU, Traumatic Brain Injury.

\section{INTRODUCTION}

Traumatic brain injury (TBI) is defined as an alteration in brain function caused by an external force. It varies from mild (including concussion) to moderate to severe TBI. It constitutes a major health and socioeconomic problem worldwide. It is prevalent in both low- and high-income countries and affects all age groups. It is called the 'silent epidemic' because its consequences are often not immediately visible, and TBI patients are not very vociferous ${ }^{(\mathbf{1})}$.

TBI is a complex process that is composed of overlapping phases, including primary injury, secondary injury and recovery. Primary injury represents a large category of insults at the time of insult and is directly proportional to the magnitude of the force applied to the brain. As a result, primary injury cannot be modified and is not amenable to treatment ${ }^{(2)}$.

The mechanisms contributing to the secondary events after TBI are adrenergic-mediated cerebral vasospasm and cerebral edema. Cerebral vasospasm occurs in more than one third of TBI and denotes severe injury. The onset varies from 2 to 15 posttraumatic days; with hemodynamically significant vasospasm occurs in $50 \%$ of all patients developing vasospasm ${ }^{(3)}$.
Cerebral edema is related to the structural damage or water and osmotic imbalance induced by the primary or secondary injury. Thus, effective treatment of brain edema would include reduction of hydrostatic capillary pressure and preservation of normal colloid osmotic pressure ${ }^{(4)}$.

Propranolol may have beneficial effects over other beta blockers in patients with TBI as it has excellent penetration into central nervous system owing to its lipophilic properties. Also, it is found to be associated with improvement in cerebral perfusion and reduction in cerebral hypoxia. In addition, it decreases catabolism and oxygen consumption in hyperadrenergic states ${ }^{(5)}$.

The purpose of the study was to evaluate the effect of beta blockers (propranolol) on patients with acute TBI regarding their roles in management of paroxysmal sympathetic hyperactivity during first week in moderate and severe traumatic brain injury (TBI) in emergency department and regarding their adverse effects. 


\section{PATIENTS AND METHODS}

This is prospective interventional study (Randomized Controlled Trials (RCT)) carried out on 400 patients with TBI who were admitted at Mansoura University Emergency Hospital, which is a level 1 trauma center with about 250,000 visits and 25000 trauma cases admission per year; through one year from January 2020 to October 2021.

Inclusion criteria: Age $\geq 18$ years, both genders, moderate (GCS: 9-12) and severe (GCS: 3-8) TBI, ICU admission and presented within 12 hours of injury.

Exclusion criteria: Pre-existing brain dysfunction, history of heart diseases, history of obstructive lung diseases, allergy to propranolol, mild (GCS: 13-15) TBI, patients who didn't receive propranolol within 12 hours of injury, non-survivable injuries: Maximal grade of AIS (AIS =6), current use of $\beta$-blockers, pregnant women and patients' relatives who refused to be enrolled in the study. The primary survey:

The initial resuscitation occurs concurrently with primary assessment. When a life-threatening condition is found, immediate corrective actions must be taken, and its effects evaluated before moving on to the next step. The primary assessment should proceed with using the "ABCDE" approach.

A. Airway and cervical Spine: The airway is the first priority in the resuscitation phase. GCS score $\leq 8$ during the initial evaluation is an indication for intubation. The cervical spine must be stabilized while establishing a patent airway and must remain immobilized until cervical spine injury has been excluded. In order to protect the cervical spine, open the air way using the modified jaw thrust maneuver without traction then replace it with neck collar once airway is secured

B. Breathing and ventilation: Adequate gas exchange is required to prevent hypoxia and hypercapnia as causes of secondary brain injury. The goal was to maintain $\mathrm{SaO}_{2}$ of $>90 \%$ (monitored via pulse oximetry) and $\mathrm{PaCO}_{2}$ of 35-40 mmHg. The respiratory rate used was 10-14 breaths/min. Hyperventilation was used as a temporary measure if clinical signs of herniation existed (e.g. unilateral or bilaterally dilated pupil), until the signs of herniation resolved

C. Circulation and bleeding control: Adequate cerebral perfusion pressure (CPP) was tried to be maintained by keeping adequate blood pressure and avoiding hypotension. For adults, systolic BP was maintained $>100 \mathrm{mmHg}$. Hypotensive patients were treated with two wide bore IV cannulae and rapid infusion of isotonic fluids (20-40 ml/kg of normal saline). Hypotonic fluids were avoided as they may worsen brain edema

D. Disability and neurologic assessment: Rapid neurological assessment is performed to define the level of consciousness, using the GCS and pupils size, symmetry and reaction and any lateralizing signs.
E. Exposure and environment control: The patients must completely undressed by cutting off the clothes to allow complete examination. After examination, try to prevent heat loss with warming devices, warmed blankets, etc.

To complete the primary survey, all polytrauma unstable patients were exposed in the resuscitation room to the following:

1. FAST (Focused assessment sonography for trauma patient): in polytrauma patients for possible internal hemorrhage.

2. Portable chest and pelvis X-ray: Anteroposterior supine view for unstable patients using shimadzu collimator $r$-20c portable $x$-ray device.

The secondary survey:

I. After initial resuscitation effort, all patients were subjected to full history taking including age, gender, mode and time of trauma, time of arrival and resuscitation.

II. AMPLE History taking:
$\mathbf{A}=$ Allergies
$\mathbf{M}=$ Medication currently used.
$\mathbf{P}=$ Past illnesses/Pregnancy.
$\mathbf{L}=$ Last meal.
$\mathbf{E}=\mathbf{E v e n t s / E n v i r o n m e n t ~ r e l a t e d ~ t o ~ i n j u r y . ~}$

III. Clinical examination of the patients at the trauma room including vital signs, local examination, neurological examination and complete general examination.

IV. Investigations: Laboratory tests, CT brain and ECG.

V. Intervention:

- The patients who met the inclusion criteria were randomly and equally divided into propranolol group and control group.

\section{Propranolol group:}

$>$ Who received propranolol at $1 \mathrm{mg}$ intravenous (IV) every $6 \mathrm{~h}$ starting within 6-12 $\mathrm{h}$ of admission for a minimum of 48 hours.

$>$ When they were transferred to ward, the dosage of propranolol was changed to 40 mg PO twice daily.

$>$ Primary study end points were bradycardia events (HR $<60 \mathrm{bpm}$ ) or hypotension events (SBP $<90 \mathrm{~mm} \mathrm{Hg}$ ) during the first $72 \mathrm{~h}$.

2. Control group: who received $0.9 \%$ normal saline in the same order but didn't receive propranolol.

- All patients with TBI received the standard treatment protocols. Data was recorded in the checklist by interview and patients' charts.

\section{Ethical considerations:}

Informed written consent was obtained from the relatives of the patients sharing in the study. 
Confidentiality and personal privacy were respected in all levels of the study. Collected data were not used for any other purpose. An approval of the study was obtained from Mansoura University academic and ethical committee.

\section{Statistical analysis:}

Data were fed to the computer and analyzed using IBM SPSS software package version 20.0. Qualitative data were expressed as number and percentage and compared by Chi-square $\left(\chi^{2}\right)$ test. Quantitative data were expressed as mean, standard deviation, median (minimum and maximum) and compared by the unpaired (T) test. All tests were 2 tailed. P value < 0.05 was considered significant.

\section{RESULTS}

Most of the studied patients in propranolol and control groups were males of middle age. There were no significant statistical differences in the demographic parameters between both groups (Table 1).

Table (1): Demographic data of the studied cases

\begin{tabular}{|c|c|c|c|}
\hline & $\begin{array}{c}\text { Propranolol } \\
\text { group } \\
(\mathbf{N}=\mathbf{2 0 0})\end{array}$ & $\begin{array}{l}\text { Control group } \\
\qquad(\mathrm{N}=\mathbf{2 0 0})\end{array}$ & P value \\
\hline \multicolumn{4}{|l|}{ Age } \\
\hline Mean \pm SD & $34.7 \pm 9.6$ & $33.9 \pm 10.1$ & \multirow{2}{*}{0.4173} \\
\hline Median (Min-Max) & $29(19-71)$ & $31(19-66)$ & \\
\hline \multicolumn{4}{|l|}{ Gender } \\
\hline Male & $167(83.5 \%)$ & $159(79.5 \%)$ & \multirow{2}{*}{0.3674} \\
\hline Female & $33(16.5 \%)$ & $41(20.5 \%)$ & \\
\hline
\end{tabular}

$\mathrm{t}$ : student $\mathrm{t}$ test

$\chi 2:$ Chi-square test (Table 2).

The differences between propranolol and control group regarding mode of trauma were not significant

Table (2): Modes of trauma in the studied cases

\begin{tabular}{|c|c|c|c|c|}
\hline Mode of trauma & $\begin{array}{c}\text { Propranolol group } \\
(\mathbf{N = 2 0 0})\end{array}$ & $\begin{array}{c}\text { Control group } \\
(\mathbf{N}=\mathbf{2 0 0})\end{array}$ & $\begin{array}{c}\text { Test of } \\
\text { significance } \\
(\chi 2)\end{array}$ & P value \\
\hline MVC & $77(38.5 \%)$ & $70(35 \%)$ & 0.387 & 0.5338 \\
\hline RTA & $54(27 \%)$ & $61(30.5 \%)$ & 0.439 & 0.5074 \\
\hline Struggle & $50(25 \%)$ & $43(21.5 \%)$ & 0.504 & 0.4776 \\
\hline FFH & $19(9.5 \%)$ & $15(7.5 \%)$ & 0.289 & 0.5907 \\
\hline
\end{tabular}

$\chi 2$ : Chi-square test

The most common CT brain finding in propranolol and control group was ICH followed by, brain edema, $\mathrm{SDH}, \mathrm{EDH}, \mathrm{SAH}$, and fracture base with no significant difference between both groups (Table 3 ).

Table (3): Analysis of CT brain findings in the studied groups

\begin{tabular}{|c|c|c|c|c|}
\hline CT findings $^{\#}$ & $\begin{array}{c}\text { Propranolol group } \\
(\mathbf{N = 2 0 0})\end{array}$ & $\begin{array}{c}\text { Control group } \\
(\mathbf{N = 2 0 0})\end{array}$ & $\begin{array}{c}\text { Test of } \\
\text { significance }(\chi 2)\end{array}$ & P value \\
\hline EDH & $26(13 \%)$ & $29(14.5 \%)$ & 0.0843 & 0.7715 \\
\hline SDH & $33(16.5 \%)$ & $39(19.5 \%)$ & 0.423 & 0.5152 \\
\hline SAH & $26(13 \%)$ & $18(9 \%)$ & 1.251 & 0.2633 \\
\hline ICH & $60(30 \%)$ & $72(36 \%)$ & 1.368 & 0.2421 \\
\hline IVH & $69(34.5 \%)$ & $58(29 \%)$ & 1.154 & 0.2828 \\
\hline Brain edema & $37(18.5 \%)$ & $44(22 \%)$ & 0.557 & 0.4554 \\
\hline Fracture base & $17(8.5 \%)$ & $14(7 \%)$ & 0.14 & 0.7084 \\
\hline
\end{tabular}

\# CT findings are not mutually exclusive, so totals can be $>100 \% \cdot \chi 2$ : Chi-square test

The clinical assessment parameters after 7 days of admission showed high significant statistical differences between the two groups. These parameters included heart rate, systolic BP, and GCS (Table 4). 
Table (4): Clinical assessment of the studied cases after 7 days of admission

\begin{tabular}{|c|c|c|c|}
\hline & $\begin{array}{c}\text { Propranolol } \\
\text { group } \\
(\mathbf{N = 2 0 0})\end{array}$ & $\begin{array}{c}\text { Control group } \\
(\mathbf{N = 2 0 0})\end{array}$ & \multirow{2}{*}{ P value } \\
\hline \multicolumn{5}{|c|}{ Heart rate (beats/minute) } \\
\hline Median (Min- Max) & 75 & 90 & \multirow{2}{*}{$<0.0001^{* *}$} \\
\hline Mean \pm SD & $78.1 \pm 5.7$ & $107.8 \pm 7.4$ & \multirow{2}{*}{$<0.0001^{* *}$} \\
\hline \multicolumn{5}{|c|}{ Systolic BP (mm Hg) } \\
\hline Median (Min- Max) & 110 & 140 & \multirow{2}{*}{$<0.0001^{* *}$} \\
\hline Mean \pm SD & $110.4 \pm 25.6$ & $142.9 \pm 4.1$ & \\
\hline Median (Min- Max) & 9 & 7 & \\
\hline Mean \pm SD & $9.3 \pm 2.93$ & $7.9 \pm 1.21$ & \\
\hline
\end{tabular}

$\mathrm{t}$ : student $\mathrm{t}$ test

** High statistically significant difference

The clinical outcome was assessed from the neurologic and cardiac sides. The difference was significant (Table 5).

Table (5): Neurologic and cardiac effects of propranolol on the studied cases

\begin{tabular}{|c|c|c|c|c|}
\hline & $\begin{array}{c}\text { Propranolol } \\
\text { group } \\
(\mathbf{N}=\mathbf{2 0 0})\end{array}$ & $\begin{array}{l}\text { Control group } \\
\quad(\mathbf{N}=\mathbf{2 0 0})\end{array}$ & $\begin{array}{c}\text { Test of } \\
\text { significance } \\
(\chi 2)\end{array}$ & $P$ value \\
\hline \multicolumn{5}{|c|}{ Neurologic (GCS) } \\
\hline Improved & $68(34 \%)$ & $55(27.5 \%)$ & \multirow{3}{*}{12.989} & \multirow{3}{*}{$0.0015^{*}$} \\
\hline The same & $118(59 \%)$ & $107(53.5 \%)$ & & \\
\hline Deteriorated & $14(7 \%)$ & $38(19 \%)$ & & \\
\hline \multicolumn{5}{|c|}{ Cardiac (ECG) } \\
\hline Tachyarrhythmias & $6(3 \%)$ & $39(19.5 \%)$ & \multirow{3}{*}{112.204} & \multirow{3}{*}{$<0.0001 * *$} \\
\hline Ischemic changes & $7(3.5 \%)$ & $43(21.5 \%)$ & & \\
\hline Cardiomyopathies & $3(1.5 \%)$ & $8(4 \%)$ & & \\
\hline
\end{tabular}

t: student $\mathrm{t}$ test

Significant difference $\chi 2$ : Chi-square test

** High statistically significant difference

The secondary outcome assessment parameters showed significant statistical differences in favor of propranolol group (Table 6).

Table (6): Outcome of the studied cases

\begin{tabular}{|c|c|c|c|}
\hline & $\begin{array}{c}\text { Propranolol group } \\
(\mathrm{N}=200)\end{array}$ & $\begin{array}{c}\text { Control group } \\
(\mathrm{N}=200)\end{array}$ & $P$ value \\
\hline \multicolumn{4}{|c|}{ Hospital Length Of Stay (LOS) } \\
\hline \multicolumn{4}{|c|}{ A. ICU LOS } \\
\hline Mean \pm SD & $14.4 \pm 11.9$ & $17.9 \pm 10.7$ & $0.0021^{*}$ \\
\hline \multicolumn{4}{|c|}{ B. Ward LOS } \\
\hline Mean \pm SD & $6.9 \pm 7.3$ & $8.8 \pm 6.9$ & $0.0078^{*}$ \\
\hline \multicolumn{4}{|c|}{ Mechanical ventilation } \\
\hline & $103(51.5 \%)$ & $95(47.5 \%)$ & \\
\hline Ventilation days & $2.6 \pm 7.3$ & $5.9 \pm 12.1$ & $0.0201^{*}$ \\
\hline \multicolumn{4}{|c|}{ Mortality rate } \\
\hline Died & $21(10.5 \%)$ & $37(18.5 \%)$ & \multirow{2}{*}{$0.0332 *$} \\
\hline Survived & $179(89.5 \%)$ & $163(81.5 \%)$ & \\
\hline \multicolumn{4}{|c|}{ Unfavorable Outcome (GOS) at discharge } \\
\hline & $51(28.5 \%)$ & $64(39.4 \%)$ & $0.0464 *$ \\
\hline
\end{tabular}

$\mathrm{t}$ : student $\mathrm{t}$ test

$\chi 2$ : Chi-square test

*Significant difference 


\section{DISCUSSION}

In this study, most of the studied patients were of middle age. Male gender predominated in propranolol and control groups. The differences in demographic data between both groups were not statistically significant. This is in agreement with Ahl and others ${ }^{(6)}$; who studied the effect of early $\beta$ blocker in patients with isolated, severe TBI; who stated that the majority of the studied patients in both groups were males $(75 \%$ and $78.9 \%)$ at their middle age (47.2 \pm 14$)$ and $(47.9 \pm 15.8)$ years old without any statistical differences in $\beta$-blocker (BB) and non $\beta$ blocker (non-BB) groups. In contrast, Ley and his coworkers ${ }^{(5)}$; who studied the effects of $\beta$-blockers in critically ill patients with TBI in multicenter study; reported that most patients were of old age in $\beta$ blocker (BB) group $(57 \pm 22)$ and no $\beta$-blocker (no BB) group $(49 \pm 21)$ with significant statistical difference between both groups. Male gender prevailed in both groups (70\% vs. $68 \%)$ without significant difference. But, Murry and his assistants ${ }^{(7)}$; who evaluated the effect of early propranolol after TBI; published that propranolol group was significantly older than control group $(47.9 \pm 18.8$ vs. $27.7 \pm 11.4$ years old; p <0.01) respectively. While, most of the patients in both groups were males ( $78 \%$ vs. $70 \%$; $\mathrm{p}=0.58$ ).

In the present study, the modes of trauma in both groups were closely approximated without significant differences. The most common mode of trauma was MVC, followed by RTA, struggle, and in propranolol and control groups. Conversely, Ley and his coworkers (5) reported that there were significant statistical differences in the modes of trauma between BB and no BB group. The modes of trauma were FFH in (43\% vs. $35 \%)$; MVC in $(27 \%$ vs. $30 \%)$; RTA in (14\% vs. $15 \%)$ and other modes in (16\% vs. $20 \%$ ) in both groups respectively.

Mechanism of injury can be defined as the physical circumstances causing the injury. Assessment of injury mechanisms is frequently used to support clinical and resource decision-making in the pre-hospital and emergency department environments. But, there is some debate as several studies have shown that knowledge of injury mechanism doesn't correlate well with severity of anatomical injury or physiological derangement, whereas other studies have demonstrated conversely (8).

In the current study, the admission CT brain findings in both groups were closely approximated without significant statistical differences. The CT brain findings were $\mathrm{ICH}$, followed by $\mathrm{IVH}$, brain edema, SDH in, EDH, SAH, and fracture base in propranolol and control groups. Similarly, Ahl and others ${ }^{(6)}$ stated that the CT brain findings were closely approximated in BB and non-BB groups. The
CT findings were SDH in (63.2\% vs. $67.1 \%)$; ICH in (13.2 vs. $10.5 \%)$; EDH in (11.8\% in both groups); DAI in (5.3\% in both groups) and SAH in $5.3 \%$ in both groups) respectively. However, Ley and his coworkers ${ }^{(5)}$ reported that the initial $\mathrm{CT}$ brain findings were significantly different between $\mathrm{BB}$ and no BB groups in $\mathrm{EDH}, \mathrm{SDH}$, and $\mathrm{ICH}$. The CT findings were SAH (62\% vs. $65 \%)$; SDH (62\% vs. $56 \%$ ); ICH (25\% vs. $16 \%)$; contusion ( $31 \%$ in each group); EDH (8\% vs. 11\%); and DAI (in 3\% in each group) respectively.

The reason why mild TBI was excluded in the studied cases was that catecholamine surge, which is associated with PSH is proportional to the severity of TBI. Thus, moderate and severe TBI were enrolled in this study

In the present study, the follow up clinical assessment parameters after 7 days of admission had high significant statistical differences parameters were better in propranolol group. They included heart rate, systolic BP, and GCS. In contrast, Murry and his assistants ${ }^{(7)}$ published that the mean number of hypotensive events per patient was similar in control and propranolol groups (0.5 \pm 1 vs. $0.8 \pm 1.8$, $\mathrm{P}=0.6$ ). The average lowest SBP for those patients with a hypotensive event was also similar (control $82.9 \pm 1.0$ vs. propranolol $83.2 \pm 1.8 \mathrm{~mm} \mathrm{Hg}, \mathrm{P}=0.95$ ). More bradycardia events were noted in control (5.8 \pm 7.2 vs. $1.6 \pm 4.6, \quad \mathrm{P}=0.047)$, although no difference was noted in the mean HR per bradycardic event (control 54.7 \pm 5.8 vs. propranolol 55.4 \pm 1.6 bpm, $\mathrm{P}=0.76$ ).

In the current study, the clinical outcome of the studied cases were obviously better in propranolol group. Both the neurologic examination; according to GCS; and the cardiac examination; according to ECG, were improved significantly more in the propranolol group than the control one. Similarly, in a randomized clinical trial; carried out by Cruickshank and others ${ }^{(9)}$; of patients suffering acute head injury, $\beta$-blocker was associated with significant reduction in the development of supraventricular tachycardia, ST segment and T wave changes and prevented cardiac necrosis seen at autopsy. Of the observed deaths in the cohort study; conducted by Khalili and his colleagues ${ }^{(10)}$; of isolated severe TBIs in the current trial, 79\% $(n=15)$ were of cardiac nature. Only four deaths were of noncardiac origin.

In this study, the secondary outcome assessment parameters were significantly better in propranolol group. The parameters were ICU LOS, ward LOS, mechanical ventilation with ventilation periods of these patients, mortality rate, and unfavorable GOS of survived patients. Correspondingly, Murry and his assistants (7) published that the secondary outcome parameters 
were better in propranolol group with significant statistical differences in hospital and ICU LOS. Hospital LOS (15.4 \pm 15.8 vs. $30.4 \pm 17$ days, $p=0.02)$ and ICU LOS ( $10 \pm 13$ vs. $19.1 \pm 10.2$ days, $\mathrm{p}=0.05)$ were lower in propranolol group. On the other hand, mortality rates were similar between groups $(10 \%$ versus $10.7 \%, \mathrm{P}=0.9)$. As well, Ahl and others ${ }^{(6)}$ stated that the secondary outcome parameters were better in BB than non-BB group with significant statistical difference only in hospital LOS. These parameters were ICU LOS (8.5 \pm 11.7 vs. 10.8 \pm 9.1$)$; hospital LOS (18 \pm 24.9 vs. $26.8 \pm 21.7)$; mortality rate (11.8\% vs. $7.9 \%)$; and unfavorable GOS at discharge (88.2\% vs. $89.5 \%)$ respectively.

Also, Ley and his coworkers ${ }^{(5)}$ reported that the mortality rate was significantly lower in patients who received $\beta$-blockers (13.8\% vs. $17.7 \%$, $\mathrm{p}=0.013)$. Despite the non-beta blocker patients having a more favorable neurological score (GOS of 4 or 5) at hospital discharge, this difference was not significant after adjusting for the confounding variables. The hospital stay was significantly higher in the $\beta$-blockers group $(21 \pm 25$ vs. $10 \pm 37$ days, $p$ $<0.01)$. After adjusting for all confounding factors, the beta blockers group continued to have a significantly longer hospital stay.

On the other hand, Ko and his colleagues (11) revealed that propranolol group had only lower mortality rate $(6.4 \%$ vs. $13 \%)$; but more ventilation days (5.9 \pm 12 vs. $2.6 \pm 7.3$ days), more hospital LOS (12.5 \pm 14.5 vs. 9.2 \pm 9.6 days), and more ICU LOS (6.6 \pm 9 vs. $4.6 \pm 6.5$ days). There was high significant statistical difference $(\mathrm{P}<0.001)$ only in ventilator days in non-propranolol group.

The improved survival and functional outcome in the present study may be a result of improved oxygenation and metabolism in the injured brain due to an improved cerebral circulation, which leads to better healing of the injured brain, in addition to the cardioprotective effects of early propranolol administration in the studied cases.

\section{CONCLUSION}

Early propranolol administration is associated with post-head injury cardioprotective and neuroprotective effects, lower hospital resources use and better functional outcome.

\section{REFERENCES}

1. Peters M, Gardner R (2018): Traumatic brain injury in older adults: do we need a different approach? Concussion, 3(3): CNC56.

2. Prakash R, Carmichael S (2015): Blood-brain barrier breakdown and neovascularization processes after stroke and traumatic brain injury. Current opinion in neurology, 28(6), 556.

3. Schroeppel T, Sharpe J, Magnotti L et al. (2014): Traumatic brain injury and $\beta$-blockers: not all drugs are created equal. Journal of Trauma and Acute Care Surgery, 76(2): 504-509.

4. Garvin R, Venkatasubramanian C, Lumba$\begin{array}{llll}\text { Brown } & \mathrm{A} & \text { et }\end{array}$ (2015): Emergency neurological life support: traumatic brain injury. Neurocritical Care, 23(2), 143-154.

5. Ley E, Berry C, Mirocha J et al. (2010): Mortality is reduced for heart rate 80 to 89 after traumatic brain injury. Journal of Surgical Research, 163(1): 142145.

6. Ahl R, Thelin E, Sjölin G et al. (2017): $\beta$-Blocker after severe traumatic brain injury is associated with better long-term functional outcome: a matched case control study. European Journal of Trauma and Emergency Surgery, 43(6), 783-789.

7. Murry J, Hoang D, Barmparas G et al. (2016): Prospective evaluation of early propranolol after traumatic brain injury. Journal of Surgical Research, 200(1): 221-226.

8. Greaves I, Porter K, Garner J (2008): Trauma care manual. Second Edition. Mechanism of Injury. CRC Press. 11-16.

9. Cruickshank J, Degaute J, Kuurne T et al. (1987): Reduction of stress/catecholamine-induced cardiac necrosis by beta1-selective blockade. The Lancet, 330(8559): 585-589.

10. Khalili H, Ahl R, Paydar S et al. (2020): Betablocker therapy in severe traumatic brain injury: a prospective randomized controlled trial. World Journal of Surgery, 44(6):1844-1853.

Ko A, Harada M, Barmparas G et al. (2016): Early propranolol after traumatic brain injury is associated with lower mortality. Journal of Trauma and Acute Care Surgery, 80(4), 637-642. 